\title{
Birth Preparedness and Complication Readiness in Uttar Pradesh, India
}

\author{
Kaushlendra Kumar \\ Manager-Data \& Quality Assurance, Evidence Action, New Delhi, India \\ Email:kkd.iips@gmail.com \\ Received 20 January 2016; accepted 23 April 2016; published 26 April 2016 \\ Copyright (C) 2016 by author and Scientific Research Publishing Inc. \\ This work is licensed under the Creative Commons Attribution International License (CC BY). \\ http://creativecommons.org/licenses/by/4.0/ \\ (c) (i) Open Access
}

\section{Abstract}

The objective of this study is to investigate the subject of birth preparedness and complication readiness to tackle the obstetric complications. Birth preparedness and complication readiness is studied based on husband's response. Emergency birth preparedness has been promoted to address delays in seeking skilled care at birth. However, little evidence is available for birth preparedness and its key covariates. Therefore, to examine the level of birth preparedness, this study has used primary data collected from the selected district of Uttar Pradesh. The information in this study may be valuable to Indian health policy makers and programme implementers who wish to lower the prevailing high maternal mortality in the country. This paper is based on the primary data collected from 33 husbands of deceased women and 150 husbands of surviving mothers from one selected district of the state of Uttar Pradesh, India. Birth preparedness and complication readiness is measured using series of questions. The husbands were asked whether they followed the following key desired steps while their wife was pregnant with last child: 1) thinking about the measures to be taken in case of life danger; 2) being aware about the delivery date of wife; 3) saving money for meeting delivery expenses; 4) discussing plans with close family members; 5) keeping ready clean cotton and other necessities; 6) identifying a hospital to go in case of emergency; 7) arranging transportation and 8) arranging dai/doctor. Taking at least five steps were considered being well-prepared. Frequency distribution and cross tabulation analysis were done and logistic regression model was applied to understand independent effect of key covariates. Proportion test and t-test were also applied to check the statistical significance in two groups. It was found that different steps of birth preparedness were not planned in case of all pregnancies. Many respondents did not take any step about birth preparedness or they prepared only for few steps only. Findings from logistic regression suggest that controlling the effect of other covariates, if wife registered her name with any hospital or doctor for antenatal care (ANC), the level of preparedness was significantly higher compared to those who were not registered for ANC services. Similarly, the husbands who reported that men should get involved in deciding the place of delivery were significantly positively associated with well birth preparedness. 
Keywords

Birth Preparedness, Complication Readiness, Men, Uttar Pradesh, and India

\section{Introduction}

Birth preparedness and complication readiness (BPCR) is a strategy employed by numerous groups implementing safe motherhood programs; however, the application of the concept is not uniform and there is no particular definition of the terms. At the same time, many packages that address birth preparedness and complication readiness promote the following: 1) preparation for normal birth by selecting skill birth attendant and place of delivery; 2) preparation of essential items for delivery; 3) knowledge of danger signs for mother and newborn; 4) knowledge of where and to whom to go in case of an emergency; 5) arranging access to funds and means for emergency transportation; and 6) prior identification of blood donors [1]. A program focusing on birth planning in Bangladesh defined birth planning as taking a series of steps prior to birth to ensure that a pregnant woman was prepared for normal birth and complications. Key messages viz. self-care during pregnancy and childbirth, knowledge of danger signs, identification of a trained birth attendant, prepare for a clean childbirth, identification of health facility to go in case of emergency, plan for pregnancy, delivery and post-delivery complications, including money savings and arrangement of transport were included in the study [2]. Inadequate funds and transportation facilities were key causes of delay in deciding to seek care and in reaching health facilities. Therefore, interventions to address these problems included a community loan program and transportation systems [3] [4].

To address supply side of BPCR, it can be expanded to the provider, facility and policymaker levels. Promoting BPCR among these functionaries can reduce delays in providing appropriate care at the health. By including these additional levels, program recognizes that factors causing three phases of delays arise from many different sources, and therefore functionaries across multiple levels share the responsibility for preparing for birth and being ready in order to save the lives of women. Further, programming tool entitled "Birth Preparedness and Complication Readiness: A Matrix of Shared Responsibility" summarizes actions to prepare for birth corresponding to each level. At the individual level, pregnant women and their husbands can prepare by learning to recognize danger signs that may indicate life-threatening complications for the mother and baby, identifying a skilled provider and a birth location, saving money, and arranging for transportation. Communities and families can prepare by making arrangements for money, transport, or a blood donor to assist a woman and her family in reaching and receiving care in case of an obstetric complications and emergency. Facilities can be prepared by having the required equipment, supplies, and support systems available. At the provider level, medical personnel can prepare themselves by acquiring necessary knowledge and skills needed to attend to normal childbirth and manage the complications. Policymakers can institute evidence-based healthcare policies and assure adequate funding for maternal and new born healthcare services [5].

A paper highlighted relationship between the elements of birth-preparedness and complication readiness and the use of a skilled provider at delivery. They found that after controlling for average distance to health facility, number of antenatal care visits, education of women, and parity, planning to save money was associated with giving birth with the assistance of a skilled provider. However, knowledge of danger signs, planning for a skilled provider at delivery, and planning for transportation in the case of emergency were not significantly associated with giving birth with the assistance of a skilled provider [6]. Other studies have also examined the relationship between birth-preparedness and complication readiness and use of skilled providers at delivery. The money saved by a woman or her family can pay for health services and supplies, vital for transport, or other costs such as loss of work. Likewise, if a woman can afford to pay for these costs, she is more likely to seek care [7]. Even when money is available, it can be difficult to secure transport at the last minute after a complication has occurred. Lack of money and transportation are barriers to seeking care as well as identifying and reaching medical facilities [8]. Many other studies also reveal that long delay in obtaining care during obstetric emergencies contribute heavily to high maternal death rate. Poor roads, long distance, a lack of vehicles, and lack of family or community planning for getting health care in an emergency were identified as major reasons for delays in obtaining care [9] [10]. 
Birth preparedness and complication readiness reduces delays in deciding to seek care in two ways. First, birth preparedness motivates people to plan to have a skilled provider at every birth. If women and families make the decision to seek care before the onset of labour, and they successfully follow through with this plan, the woman will receive care before developing any potential complications during childbirth, thus avoiding the first two delays completely. Second, complication readiness raises awareness of danger signs among women, families, and communities, thereby improving problem recognition and reducing the delay in deciding to seek care. Birth preparedness and complication readiness encourages women, households, and communities to make arrangements such as identifying or establishing available transport, setting aside money to pay for service fees and transport, and identifying a blood donor in order to facilitate quick decision making and reduce delays in reaching care once a problem arises. In sum, at the demand level, birth preparedness and complication readiness promotes the use of a skilled provider at birth through increasing demand and improving access. A descriptive cross-sectional study to evaluate birth preparedness and complication readiness among antenatal care clients at antenatal care clinic at Kenyatta National Hospital, Nairobi, Kenya report that 87 percent of the respondents were aware of their expected date of delivery, 84 percent had set aside funds for transport to hospital during labour while 63 percent had funds for emergencies. Level of education positively influenced birth preparedness. Respondent's knowledge of danger signs in pregnancy was low. Many respondents did not know about birth preparedness and had no plans for emergencies [11]. Another study found that husband and in-laws play dominant role in decision-making. Further, significant proportion of mothers hadn't planned for place of delivery. This finding can be utilized for targeting men in information, education and communication (IEC) activities [12].

A study to assess the knowledge and practices towards birth preparedness and complication readiness and associated factors among women of reproductive age group in Ethiopia reveals poor knowledge and practices of birth preparedness and complication readiness. Further, community education about preparation for birth and its complication and empowerment of women through expansion of educational opportunities are important steps in improving birth preparedness. Emphasis should be given to preparation for birth and its complication and health facility must provide information and education to all pregnant women during antenatal care [13]. In a program in Uttar Pradesh, community-based workers counselled pregnant women on maternal and new born care. Four emergency birth preparedness steps were; identifying a health facility, identifying a person to accompany the mother, arranging for transport, and saving money. This study concluded that promoting emergency birth preparedness in community-based maternal and new born care programs can increase the utilization of skilled birth attendants [14]. Emergency birth preparedness has been promoted to address delays in seeking skilled care at birth. However, little evidence is available on birth preparedness in the context of India. Making decisions about what to do in the event of obstetric complications is a complex process, but in almost all settings, women's families play a significant, sometimes dominant, role in that process. The husbands or partners of pregnant women are often the decision-makers, especially if the woman is experiencing a life threatening complications. They are also usually the ones responsible for making financial and logistical arrangements for transfer to an emergency facility [15] [16]. JHPIEGO/Maternal and Neonatal Health Program discuss that it is not the pregnant woman herself who decides on the place for childbirth, but rather her family members. Thus, BPCR initiatives must target not only the woman but also those in her family circle most likely to make that decision. In societies in general, the husband or partner is the most influential decision-maker and, even if others offer their opinions, he will be the one to make the final decision [17].

The objective of this study is to investigate the subject of birth preparedness and complication readiness to tackle the obstetric complications. Birth preparedness and complication readiness are studied based on husband's response. Emergency birth preparedness has been promoted to address delays in seeking skilled care at birth. However, little evidence is available for birth preparedness and its key covariates. Therefore, to examine the level of birth preparedness, this study has used data collected from the selected district of Uttar Pradesh. The information in this study may be valuable to Indian health policy makers and programme implementers who wish to lower the prevailing high maternal mortality in the country.

\section{Data and Methods}

This paper is based on the primary data collected from 33 husbands of deceased women and 150 husbands of surviving mothers from Bhadohi district of Uttar Pradesh, India. A descriptive, cross-sectional survey conducted 
in eight districts of Uttar Pradesh shows that the maternal mortality ratio in Eastern Uttar Pradesh (Gorakhpur, Basti, Varanasi and Pratapgarh) was higher (573 per 100,000 live births) compared to that in Western Uttar Pradesh (Agra, Farrukhabad, Ghaziabad and Badaun) (472 per 100,000 live births) [18]. Therefore, the present study was proposed to be conducted in any district from Eastern region of Uttar Pradesh. Consequently, Bhadohi district of Eastern Uttar Pradesh was purposively chosen and considering time and resources available for the study, data collection was restricted to only one Tehsil of the district.

Birth preparedness and complication readiness in this paper is measured using series of questions. The husbands were asked whether they followed the following key desired steps while their wife was pregnant with last child: 1) thought about the measures to be taken in case of life danger; 2) aware about the delivery date of wife; 3) saved money for meeting delivery expenses; 4) discussed plans with close family members; 5) kept ready clean cotton and other necessities; 6) identified a hospital to go in case of emergency; 7) arranged transportation and 8) arranged dai/doctor. Taking at least five steps was considered being well-prepared. A total of 200 men (i.e. 150 husband of surviving women and 50 husbands of deceased women) were targeted to be interviewed. However, finally only 183 husbands (i.e. 150 of surviving women and 33 of deceased women) could be interviewed. Other 17 husbands could not be interviewed as three of them could not be contacted, three of them were migrated to other state, one was died and other 10 were again not possible to interview as maternal death took place at maternal home of deceased women (see Table 1). Frequency distribution and cross tabulation analysis was done and logistic regression model was applied to understand independent effect of key covariates. Proportion test and t-test was also applied to check the statistical significance in two groups.

\section{Results}

1) Profile of the husbands: It is evident from table that out of total more than half of the respondents (53\%) belong to the age group of 25 - 35 years. One-third of the respondents were of less than 25 years and remaining were of 35 years and above. The age distribution is observed similar among the husbands of surviving women. However, the age distribution of husbands of deceased women shows that more than half $(52 \%)$ of the husbands belong to $25-35$ years age group. The distribution of sample by place of residence shows that majority of respondents (95\%) belong to rural areas. The religion wise distribution is nearly in same line as place of residence. Majority of the respondents belong to Hindu religion (94\%). The highest percentage of the respondents (46\%) belongs to the other backward classes (OBCs) followed by scheduled castes/scheduled tribes (SCs/STs) group $(43 \%)$ and others caste category (11\%). More than half of the respondents were from joint families $(52 \%)$ and remaining 48 percent were from nuclear families (see Table 2).

2) Birth preparedness and complication readiness: This section provides the information on birth preparedness and complication readiness to tackle the problem that arises during pregnancy complications and delivery. It is evident from the table that more than half of the men (53\%) reported that they thought about the measures to be taken in case of life danger. This prevalence varies among husbands of deceased women (30\%) and surviving women $(57 \%)$. Over two-fifth men reported that they were aware about the delivery date of their wives and one-fifth of those working planned to take leave at the time of wife's delivery. Over half of the total husbands of deceased mothers reported that they saved money for meeting delivery expenses. However, it is found 75 percent in case of surviving mothers. One-third of the husbands of deceased mothers discussed plans with close family members compared to around half in case of surviving mothers. Only 36 percent husbands of deceased mothers reported that they identified a hospital to go in case of emergency compared to 74 percent among controls. Similarly, arrangement of transportation also varied from around two-fifth (39\%) in case of deceased mothers to three-fifth $(60 \%)$ among the survivors. Further, averages (mean, median and mode) for number of steps taken has been computed. It is evident from the table that average number of steps taken was reported less for cases (maternal deaths) compared to controls (surviving mothers). Again, it is clear that either none or only one step was taken in case of more than one third (36\%) of deceased mothers in contrast to only 12 percent in case of surviving mothers. As median number of preparedness steps is observed 5 in our sample, we have also computed the percentage of the respondents who have reported that they prepared for at least five steps. In total, 58 percent men reported that they prepared at least for five steps during last delivery/pregnancy of their wives. This prevalence varies from 36 percent among cases to 63 percent among controls and proportion test is found significant at 5\% level of significance (see Table 3).

It is clear from Table 4 that in most of the cases delivery was planned in institution among cases $(88 \%)$ and 
Table 1. Percentage distribution of men sample covered under study, Bhadohi, Uttar Pradesh, India, 2011.

\begin{tabular}{ccc}
\hline Characteristics of the respondents & Percentage & Number \\
\hline Type of respondents targeted & 75.0 & 150 \\
Husband of surviving mothers & 25.0 & 50 \\
Husband of deceased mothers & & $\mathbf{1 8 3}$ \\
\hline Interview status of husbands & $\mathbf{9 1 . 5}$ & 150 \\
Total interviewed & 75.0 & 33 \\
Husband of surviving mothers interviewed & 16.5 & 3 \\
Husband of deceased mothers interviewed & 1.5 & 3 \\
Could not be contacted & 1.5 & 1 \\
Husband migrated & 0.5 & 10 \\
\hline
\end{tabular}

Table 2. Percent distribution of men by background characteristics, Bhadohi, Uttar Pradesh, India, 2011.

\begin{tabular}{|c|c|c|c|}
\hline Background characteristics & $\begin{array}{l}\text { Husbands of deceased } \\
\text { women }\end{array}$ & $\begin{array}{c}\text { Husbands of surviving } \\
\text { women }\end{array}$ & Total \\
\hline \multicolumn{4}{|l|}{ Age } \\
\hline Less than 25 & 18.2 & 35.3 & 32.2 \\
\hline 25 to 35 years & 51.5 & 52.7 & 52.5 \\
\hline 35 years and above & 30.3 & 12.0 & 15.3 \\
\hline \multicolumn{4}{|l|}{ Residence } \\
\hline Rural & 81.8 & 98.0 & 95.1 \\
\hline Urban & 18.2 & 2.0 & 4.9 \\
\hline \multicolumn{4}{|l|}{ Religion } \\
\hline Hindu & 75.8 & 98.0 & 94.0 \\
\hline Muslim & 24.2 & 2.0 & 6.0 \\
\hline \multicolumn{4}{|l|}{ Caste } \\
\hline Scheduled castes/scheduled tribes & 45.5 & 42.0 & 42.6 \\
\hline Other backward classes & 48.5 & 46.0 & 46.4 \\
\hline Scheduled castes/scheduled tribes & 6.1 & 12.0 & 10.9 \\
\hline \multicolumn{4}{|l|}{ Education } \\
\hline Not educated & 39.4 & 39.3 & 39.3 \\
\hline Less than high school & 33.3 & 32.0 & 32.2 \\
\hline High school and above & 27.3 & 28.7 & 28.4 \\
\hline \multicolumn{4}{|l|}{ Type of family } \\
\hline Nuclear family & 48.5 & 48.0 & 48.1 \\
\hline Joint family & 51.5 & 52.0 & 51.9 \\
\hline Number & 33 & 150 & 183 \\
\hline
\end{tabular}

controls $(85 \%)$ both. Twelve percent husbands of deceased reported that last deliveries of the women took place at home as it was planned. In case of controls, 88 percent husband reported that the deliveries took place in institution against the planned 85 percent. Table 5 presents the percentage of men who reported about five steps of 
preparation to tackle the pregnancy and delivery complications by selected characteristics. The level of birth preparedness and complication readiness was found highest among men who were aged 25 - 34 years. Further,

Table 3. Percentage of men reported about different component of birth preparedness and complication readiness, Bhadohi, Uttar Pradesh, India, 2011.

\begin{tabular}{|c|c|c|c|}
\hline Birth preparedness & Cases $\left(\mathbf{P}_{1}\right)$ & Controls $\left(\mathbf{P}_{2}\right)$ & Total \\
\hline $\begin{array}{l}\text { Thought about the measures to be taken in } \\
\text { case of life danger }\end{array}$ & 30.3 & 57.3 & 52.5 \\
\hline Aware about the delivery date of wife & 39.4 & 42.0 & 41.5 \\
\hline Planned to take leave at the time of wife's delivery & 18.2 & 20.0 & 19.7 \\
\hline Saved money for meeting delivery expenses & 51.5 & 75.3 & 71.0 \\
\hline Discussed plans with close family members & 33.3 & 49.3 & 46.4 \\
\hline Kept ready clean cotton and other necessities & 66.7 & 86.0 & 82.5 \\
\hline Identified a hospital to go in case of emergency & 36.4 & 74.0 & 67.2 \\
\hline Arranged transportation & 39.4 & 60.0 & 56.3 \\
\hline Arranged dai/doctor & 42.4 & 49.3 & 48.1 \\
\hline \multicolumn{4}{|l|}{ Number of steps taken } \\
\hline 0 & 15.2 & 6.7 & 8.2 \\
\hline 1 & 21.2 & 5.3 & 8.2 \\
\hline 2 & 6.1 & 4.7 & 4.9 \\
\hline 3 & 15.2 & 12.0 & 12.6 \\
\hline 4 & 6.1 & 8.7 & 8.2 \\
\hline 5 & 9.1 & 11.3 & 10.9 \\
\hline 6 & 9.1 & 20.7 & 18.6 \\
\hline 7 & 9.1 & 18.0 & 16.4 \\
\hline 8 & 9.1 & 12.7 & 12.0 \\
\hline Mean & $3.4^{*}$ & $4.9^{*}$ & 4.7 \\
\hline Median & 3.0 & 6.0 & 5.0 \\
\hline Mode & 1.0 & 6.0 & 6.0 \\
\hline At least 5 steps taken & $36.4^{* *}$ & $62.7^{* *}$ & 57.9 \\
\hline Number & 33 & 150 & 183 \\
\hline
\end{tabular}

${ }^{*}$ t-test is found significant, $\mathrm{p}<0.05 ;{ }^{* *}$ Proportion test found significant, $\mathrm{p}<0.05$.

Table 4. Plan for place of delivery and actual place of delivery, men's report, Bhadohi, Uttar Pradesh, India, 2011.

\begin{tabular}{cccc}
\hline Birth preparedness & Cases & Controls & Total \\
\hline Plan for place of delivery & & & 14.2 \\
Home & 12.1 & 14.7 & 85.8 \\
Institution & 87.9 & 85.3 & 11.5 \\
\hline Place of delivery & & & 83.1 \\
Home & 12.1 & 11.3 & 5.5 \\
Institution & 60.6 & 88.0 & $\mathbf{1 8 3}$ \\
Others & 27.3 & 0.7 & $\mathbf{1 5 0}$ \\
\hline
\end{tabular}


Table 5. Percentage of men who reported they prepared at least for five steps of preparedness by selected characteristics, Bhadohi, Uttar Pradesh, India, 2011.

\begin{tabular}{|c|c|c|}
\hline Background characteristics & Percentage & Number \\
\hline \multicolumn{3}{|l|}{ Age of the respondents } \\
\hline Less than 24 & 54.2 & 59 \\
\hline 25 to 34 years & 61.5 & 96 \\
\hline 35 years and above & 53.6 & 28 \\
\hline \multicolumn{3}{|l|}{ Type of residence } \\
\hline Rural & 59.8 & 174 \\
\hline Urban & 22.2 & 9 \\
\hline \multicolumn{3}{|l|}{ Religion } \\
\hline Hindu & 58.7 & 172 \\
\hline Muslim & 45.5 & 11 \\
\hline \multicolumn{3}{|l|}{ Caste } \\
\hline Scheduled castes/scheduled tribes & 50.0 & 78 \\
\hline Other backward classes & 58.8 & 85 \\
\hline Others & 85.0 & 20 \\
\hline \multicolumn{3}{|l|}{ Type of family } \\
\hline Nuclear family & 58.0 & 88 \\
\hline Joint family & 57.9 & 95 \\
\hline \multicolumn{3}{|l|}{ Ever attended school } \\
\hline Yes & 63.1 & 111 \\
\hline No & 50.0 & 72 \\
\hline \multicolumn{3}{|c|}{ Education level of highest educated person in the household } \\
\hline Not educated & 47.4 & 57 \\
\hline Primary & 60.0 & 40 \\
\hline Secondary & 59.3 & 59 \\
\hline Higher & 74.1 & 27 \\
\hline \multicolumn{3}{|c|}{ Wife registered her name with any hospital or doctor } \\
\hline Yes & 74.5 & 98 \\
\hline No & 37.3 & 83 \\
\hline \multicolumn{3}{|c|}{ Man get involved in deciding the place of delivery } \\
\hline Yes & 67.7 & 133 \\
\hline No & 32.0 & 50 \\
\hline \multicolumn{3}{|c|}{ Special care a woman needs to take following childbirth } \\
\hline Yes & 67.4 & 132 \\
\hline No/don't know & 33.3 & 51 \\
\hline Total & 57.9 & 183 \\
\hline
\end{tabular}

preparedness varies by place of residence and it is found 60 percent in rural areas compared to $22 \%$ in urban areas. The differences by religion and castes are also observed. Preparedness is found more among Hindus (59\%) compared to Muslims (46\%). It is also observed that level of birth preparedness was highest among others (85\%) 
caste category followed by OBCs (59\%) and SCs/STs (50\%). No differences were observed in birth preparedness by type of family. Education is positively associated with birth preparedness.

ANC registration plays a vital role in increasing level of birth preparedness. The level of preparedness was found high if wife registered with any hospital or doctor for ANC compared to those who were not registered for ANC check-ups. Further, more than two third men who feel that they should get involved in deciding place of delivery and are aware that women need special care following the childbirth reported to prepared for at least five steps compared to their counterpart 32\% and 33\% respectively (Figure 1).

\section{Factors Associated with Birth Preparedness and Complication Readiness}

This section presents finding from logistic regression analysis showing factors associated with birth preparedness and complication readiness. It is evident from the findings that if wife registered with any hospital/health facility or doctor for antenatal check-ups, the level of preparedness found significantly higher compared to those who were not registered for ANC. Keeping other variables constant, women's registered for ANC is seven times more likely to get prepared for birth preparedness $($ O.R. $=7.06$; 95\% C.I. $=3.05,16.36)$. Similarly, respondents who have reported that men should get involved in deciding the place of delivery are significantly positively associated with level of birth preparedness. The men who perceive that men should get involved in deciding the place of delivery increases odds of preparedness steps taken by four times $(O . R .=4.24 ; 95 \%$ C.I. $=1.71,10.51)$ compared to those who have negative perception. Further, odds of birth preparedness was found low among husbands of deceased women (O.R. $=0.16 ; 95 \%$ C.I. $=0.05,0.51)$ as compared to surviving mothers (Table 6).

\section{Discussion and Conclusions}

Birth preparedness and complication readiness encourages women, households, and communities to make arrangements such as identifying or establishing available transport, setting aside money to pay for service fees and transport, and identifying a blood donor in order to facilitate quick decision making and reduce delays in reaching care once a problem arises. Birth preparedness and complication readiness reduces delays in deciding to seek care. Birth preparedness motivates people to plan to have a skilled health care provider and complication readiness raises awareness of danger signs among women, families, and communities, thereby improving problem recognition and reducing the delay in deciding to seek care. In sum, birth preparedness and complication

\section{ANC Registration and Birth Preparedness}

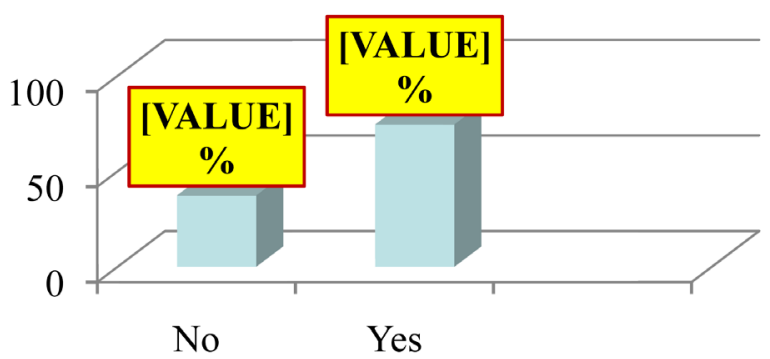

Figure 1. ANC registration and birth preparedness.

Table 6. Logistic regression analysis (likelihood of birth preparedness; dependent variable: prepared for at least 5 steps $=1$, and 0 otherwise), Bhadohi, Uttar Pradesh, India, 2011.

\begin{tabular}{|c|c|c|c|c|}
\hline \multirow{2}{*}{ Covariates } & \multirow{2}{*}{$\begin{array}{l}\text { Adjusted odds } \\
\text { ratios }\end{array}$} & \multirow{2}{*}{ P-values } & \multicolumn{2}{|c|}{ 95\% Confidence Interval } \\
\hline & & & Lower Limit & Upper Limit \\
\hline Women's registered for ANC & 7.06 & 0.000 & 3.05 & 16.36 \\
\hline Men involvement in deciding place of delivery & 4.24 & 0.002 & 1.71 & 10.51 \\
\hline Husbands of deceased women & 0.16 & 0.002 & 0.05 & 0.51 \\
\hline
\end{tabular}

Controlled variables: age of respondents, place of residence, religion, type of family, education of respondents, involvement of men in deciding place of delivery, and husbands of deceased/surviving women (cases/controls). 
readiness promotes the use of a skilled provider at birth through increasing demand and improving access. Findings reveal that different steps of birth preparedness were not planned in case of all pregnancies/births in the sample. Many respondents reported that there was no birth preparedness or they prepared only for few steps. Birth preparedness was planned for obstetric emergencies in case of large proportion of pregnancies; however, this preparedness varies in the number of steps taken.

Further, findings of the study suggested that more than half of men reported that they thought about the measures to be taken in case of life danger with significant variation among cases and controls. Over two-fifth men reported that they were aware about the delivery date of wife and one-fifth of those working planned to take leave at the time of wife's delivery irrespective of cases and controls. Over half of the husbands of deceased women reported that they saved money for meeting delivery expenses. However, the same has been found more than three-fourth for surviving mothers. One-third husbands of deceased mothers discussed plans with close family members compared to around half in case of surviving mothers. Only over one-third husbands of deceased mothers have reported that they identified a hospital to go in case of emergency compared to around three-fourth among controls. Similarly, arrangement of transportation also varied from two-fifth in case of deceased mothers to three-fifth among the surviving mothers. Results clearly indicated that there was better preparedness among surviving mothers compared to those who have died. Further, it was found that average number of steps taken was reported less for cases compared to controls and the same was found statistically significant. Again, it is clear that either none or only one step was taken in case of more than one third of deceased mothers. In total, more than fifty percent men reported that they prepared at least for five steps during last delivery/pregnancy of their wives. This proportion varies significantly among cases and controls.

Further, the factors associated with birth preparedness and complication readiness are assessed with the help of logistic regression model. Findings suggest that controlling the effect of other important covariates, if wife registered her name with any hospital or doctor for antenatal check-ups, the level of preparedness was significantly higher compared to those who were not registered for ANC services. Similarly, the husbands who reported that men should get involved in deciding the place of delivery were significantly positively associated with well birth preparedness.

\section{Acknowledgements}

Author is thankful to "The Parks Foundation, Department of Biological Anthropology, University of Cambridge, United Kingdom (UK)" for supporting this study financially and awarding "Parks Foundation Small Grants Fund" for the year 2011.

\section{References}

[1] JHPIEGO and Maternal and Neonatal Health (MNH) Program (2004) Birth Preparedness and Complication Readiness, Tools and Indicators for Maternal and New Born Health. John Hopkins, Bloomberg School of Public Health, Center for Communication Programs, Family Care International, 2004.

[2] Barbey, A., et al. (2001) Dinajpur Safe Mother Initiative Final Evaluation Report. Dhaka, CARE.

[3] Essien, E., et al. (1997) Community Loan Funds and Transport Services for Obstetric Emergencies in Northern Nigeria. International Journal of Gynecology \& Obstetrics, 59, S237-S244. http://dx.doi.org/10.1016/S0020-7292(97)00171-9

[4] Samai, O. and Sengeh, P. (1997) Facilitating Emergency Obstetric Care through Transportation and Communication, Bo, Sierra Leone. The Bo PMM Team. International Journal of Gynecology \& Obstetrics, 59, S157-S164. http://dx.doi.org/10.1016/S0020-7292(97)00161-6

[5] JHPIEGO and Maternal and Neonatal Health (MNH) (2001) Monitoring Birth Preparedness and Complication Readiness: A Matrix of Shared Responsibilities. JHPIEGO/MNH, Baltimore.

[6] Moran, A.C., Sangli, G., Dineen, R., Rawlins, B., Yaméogo, M. and Baya, B. (2006) Birth Preparedness for Maternal Health: Findings from Koupéla District, Burkina Faso. Journal of Health, Population and Nutrition, 24, 489-497.

[7] JHPIEGO and Maternal and Neonatal Health (MNH) (2001) Monitoring Birth Preparedness and Complication Readiness: A Matrix of Shared Responsibilities. JHPIEGO/MNH, Baltimore.

[8] Thaddeus, S. and Maine, D. (1994) Too Far to Walk: Maternal Mortality in Context. Social Science and Medicine, 38, 1091-1110. http://dx.doi.org/10.1016/0277-9536(94)90226-7

[9] Thomas, S., Kanenda, O., Ahluwalia, I. and Kouletio, M. (2001) Transportation for Maternal Emergencies in Tanzania: 
Empowering Communities through Participatory Problem Solving. American Journal of Public Health, 91, 10.

[10] Bhatia, J.C. (1993) Levels and Causes of Maternal Mortality in Southern India. Studies in Family Planning, 24, 310318. http://dx.doi.org/10.2307/2939224

[11] Mutiso, S.M., Qureshi, Z. and Kinuthia, J. (2008) Birth Preparedness among Antenatal Clients. East African Medical Journal, 85, 275-283. http://dx.doi.org/10.4314/eamj.v85i6.9625

[12] Deoki, N., Kushwah, S.S., Dubey, D.K., Gyan, S., Shivdasani, J.P. and Vivek, A. (2008-2009) A Study for Assessing Birth Preparedness and Complication Readiness Intervention in Rewa District of Madhya Pradesh. By Department of Community Medicine, S. S. Medical College, Rewa and National Institute of Health and Family Welfare.

[13] Muhammedawel, K. and Mesfin, A. (2014) Birth Preparedness and Complication Readiness in Robe Woreda, Arsi Zone, Oromia Region, Central Ethiopia: A Cross-Sectional Study. Reproductive Health, 11, 2-12. http://dx.doi.org/10.1186/1742-4755-11-55

[14] Rosecrans, A.M., Williams, E.K., Agrawal, P.K., Ahmed, S., Darmstadt, G.L., Kumar, V., Ahuja, R.C., Srivastava, V.K., Black, R.E., Santosham, M. and Baqui, A.H. (2008) Is Emergency Birth Preparedness Associated with Increased Skilled Care at Birth: Evidence from Rural Uttar Pradesh, India. Journal of Neonatal-Perinatal Medicine, 1, 145-152.

[15] Mother Care (2000) Mother Care's Community Assessments. Understanding Family and Community Behaviours and Practices. Mother Care Matters, 8, 1-17.

[16] Mother Care (2000) Behavioural Dimensions of Health and Survival. Mother Care Matters, 9, 1-19.

[17] JHPIEGO and Maternal and Neonatal Health (MNH) Program (2004) Birth Preparedness and Complication Readiness, Tools and Indicators for Maternal and New Born Health. John Hopkins, Bloomberg School of Public Health, Center for Communication Programs, Family Care International, 2004.

[18] Gupta, N., Kumar, S., Saxena, N.C., Deoki, N. and Saxena, B.N. (2007) Maternal Mortality in Seven Districts of Uttar Pradesh-An ICMR Task Study. Indian Journal of Public Health, 50, 3. 